\title{
Autologous Bladder Cell Carcinoma RNAs/CD40L RNA Electroporated Autologous Matured Dendritic Cells
}

National Cancer Institute

\section{Source}

National Cancer Institute. Autologous Bladder Cell Carcinoma RNAS/CD4OL RNA

Electroporated Autologous Matured Dendritic Cells. NCI Thesaurus. Code C129522.

A cell-based preparation in which autologous, mature dendritic cells (DCs) are

electroporated with in vitro transcribed (IVT) RNAs encoding for a synthetic form of Tcell protein CD40 ligand (CD40L) and IVT RNA encoding for autologous tumorassociated antigens (TAAs) derived from patient-specific bladder cell carcinoma (BCC) cells, with potential immunostimulatory and antineoplastic activities. Upon electroporation into autologous DCs, the RNA is translated and processed. BCC-specific antigenic peptides are subsequently presented via major histocompatibility complex (MHC) Class I molecules on the DCs surface. When AGS-003-BLD is reintroduced to the patient, the MHC-presented peptides interact with and activate CD8-positive T-cells, which elicits a highly specific cytotoxic T-cell (CTL) response ag ainst tumor cells expressing the patient-specific BCC TAAs. The signal cascade initiated by expression of the co-stimulatory molecule CD40L results in the secretion of the inflammatory cytokine IL-12, which further stimulates CT Ls. 